\title{
Development and first assessment of a RGBW-LED Diaphanoscope
}

\author{
Johannes Busshardt ${ }^{1}$, Nicole Sieber ${ }^{1}$, Philipp Koelbl ${ }^{1}$, Christian Lingenfelder ${ }^{2}$, Martin Hessling ${ }^{1}$ \\ ${ }^{1}$ Institute of Medical Engineering and Mechatronics, Ulm University of Applied Sciences, Ulm, Germany \\ ${ }^{2}$ Pharmpur GmbH, Königsbrunn, Germany
}

\begin{abstract}
BACKGROUND: Diaphanoscopy is an old but still useful technique in ophthalmic diagnostics. Its application suffers somewhat from the fact that the light is strongly attenuated and red-shifted in color when the eye wall is transilluminated.

MATERIAL AND METHODS: A color adjustable diaphanoscope prototype is developed based on a powerful red-green-blue-white light-emitting diode (RGBW-LED). Its optical and thermal properties are measured and tested on the porcine eyes of a local butcher. In addition, based on the technical data, the assumed retinal hazard to human eyes is assessed according to the standard DIN EN ISO 15004-2: 2007-6.

RESULTS: The investigated porcine eyes were brightly illuminated with all LED colors. The calculated values for judging the thermal and photochemical hazard were below the limits given in DIN EN ISO 15004-2: 2007-6.

CONCLUSION: Based on the standard mentioned above, there is no recognizable danger to the human retina when applied for a limited time, and at least in the porcine model, the presented RGBW-LED diaphanoscope allows an adjustable ophthalmological transillumination without the requirement of the more elaborated devices that are usually employed in operating rooms.
\end{abstract}

KEY WORDS: diaphanoscopy; RGBW illumination; photochemical hazard; thermal hazard

Ophthalmol J 2021; Vol. 6, 101-106

\section{INTRODUCTION}

Diaphanoscopy is a 150 -year-old technique attributed to the ophthalmology pioneer Albrecht von Graefe [1]. It involves transillumination of the apparently opaque eye wall, consisting of the retina, choroidea, and sclera, from the outside to the inside or in the opposite direction. The original application was primarily the detection of foreign bodies and tumors [2-9], whereas today's applications include the detection of retinal defects and detachments [10-12] and supportive imaging in vitreous surgery [13-15].
Historically, light sources were first the lens-focused light from the sun and gas flames [1]. Later, incandescent and halogen lamps came into use. Even then, the relatively low transmission of the eyewall led to the technical problem that bright transillumination of the eye is difficult to achieve without endangering the eye, e.g., thermally by the available light sources with their often strong infrared emissions.

Today's diaphanoscopic systems usually consist of filtered xenon light sources without strong infrared emissions. This light is transmitted to the sclera 
through a thin, light fiber with an applicator tip that increases the contact area with the eye. Because of the small diameter of the light guide, only a limited luminous flux reaches the eye, and even the spectral broadband xenon light is strongly attenuated as it passes through the eyewall. This is especially true for the blue spectral components, which makes the light intensity in the eye even weaker and at the same time more reddish.

For diaphanoscopic illumination of the eye's interior, therefore, a stronger illumination with a high blue component would be desirable so that higher luminous flux, particularly more blue light, reaches the eye. At the same time, it must be ensured that the patient's eye and especially the retina do not suffer thermal or photochemical damage.

Today, other diagnostic instruments like OCT (optical coherence tomography) devices exist that are very sophisticated and offer information that diaphanoscopy cannot provide. Nevertheless, diaphanoscopy has its advantages because it is relatively fast, inexpensive, and straightforward. Furthermore, it can be applied in less sterile environments as it does not require incisions in the eye like conventional fiber illuminators.

Therefore, this study aims to develop a prototype light-emitting diode (LED) diaphanoscopic system that is particularly bright and offers an adjustable emission spectrum that can be applied to achieve arbitrary illumination colors in the eye selectively. It is also capable of monochromatic illumination for special applications, such as blue excitation of the green fluorescent dye fluorescein for angiography. Despite this intended higher brightness, the patient's eye should not be endangered thermally or photochemically.

\section{MATERIAL AND METHODS}

Illumination experiments were performed in a laboratory with the porcine eyes of a local butcher. The investigations took place within about 8 hours after enucleation. The eyes were stored in a balanced salt solution (BBS) in the fridge at $4^{\circ} \mathrm{C}$ until the start of the experiments.

A central element of the illumination system was a red-green-blue-white light-emitting diode (RGBW-LED) type XM-L-Color LED (XMLCTW-A0-0000-00C2AAAB1) of Cree (Durham, USA). According to the datasheet [16], it consists of four single LED chips in a shared LED housing with expected peak wavelengths at about $625 \mathrm{~nm}$,
$530 \mathrm{~nm}$, and $460 \mathrm{~nm}$ for the color LED chips and a color temperature of about $4000 \mathrm{~K}$ for the white LED chip.

Temperature measurements during preliminary tests with the temperature sensor UT320 of UNI$\mathrm{T}$ (Dongguan City, China) revealed that the LED could become very hot at high currents. Therefore, the package was extended by about $20 \mathrm{~mm}$ (diameter $5 \mathrm{~mm}$ ) with a transparent resin Crystal Clear 202 EU of KauPo (Spaichingen, Germany) as indicated in Figure 1, and the temperature at the tip was determined again. The extended LED was integrated into an aluminum housing to cool the LED chips and avoid glare.

The emission spectra of the extended LEDs were determined with a calibrated spectroradiometer CAS 140D of Instrument Systems (Munich, Germany). With these spectra, the photochemical and thermal hazard were calculated in accordance with the international standard DIN EN ISO 15004-2: 2007-6 Ophthalmic instruments - Fundamental requirements and test methods - Part 2: Light hazard protection [18].

The most important values regarding potential hazards to the retina are the "weighted retinal visible and infrared radiation thermal irradiance" $\mathrm{E}_{\mathrm{VIR}-\mathrm{R}}$, the "weighted retinal irradiance" $E_{A-R}$, and the maximum exposure time $T_{\max }$, which can be calculated by equation (1), (2) and (3):

$$
\begin{gathered}
E_{V I R-R}=\sum_{380}^{1400} E_{\lambda} \cdot R(\lambda) \cdot \Delta \lambda \\
E_{A-R}=\sum_{305}^{700} E_{\lambda} \cdot A(\lambda) \cdot \Delta \lambda \\
t_{\text {max }}=\frac{10 \frac{\mathrm{J}}{\mathrm{cm}^{2}}}{\sum_{305}^{700} E_{\lambda} \cdot A(\lambda) \cdot \Delta \lambda}
\end{gathered}
$$

with the thermal hazard weighting function $R(\lambda)$ and the photochemical hazard weighting function $\mathrm{A}(\lambda)$ as given in DIN EN ISO 15007-2: 2007-6. To calculate the irradiances $\mathrm{E}_{\lambda}$ at the tip of the LED extension, the measured emission spectra were divided by the cross-section area of the LED elongation of about $0.2 \mathrm{~cm}^{2}$.

The control unit is based on a PI $3+$ microcomputer of the Raspberry Foundation (Cambridge, Great Britain), which is connected to a touch screen 


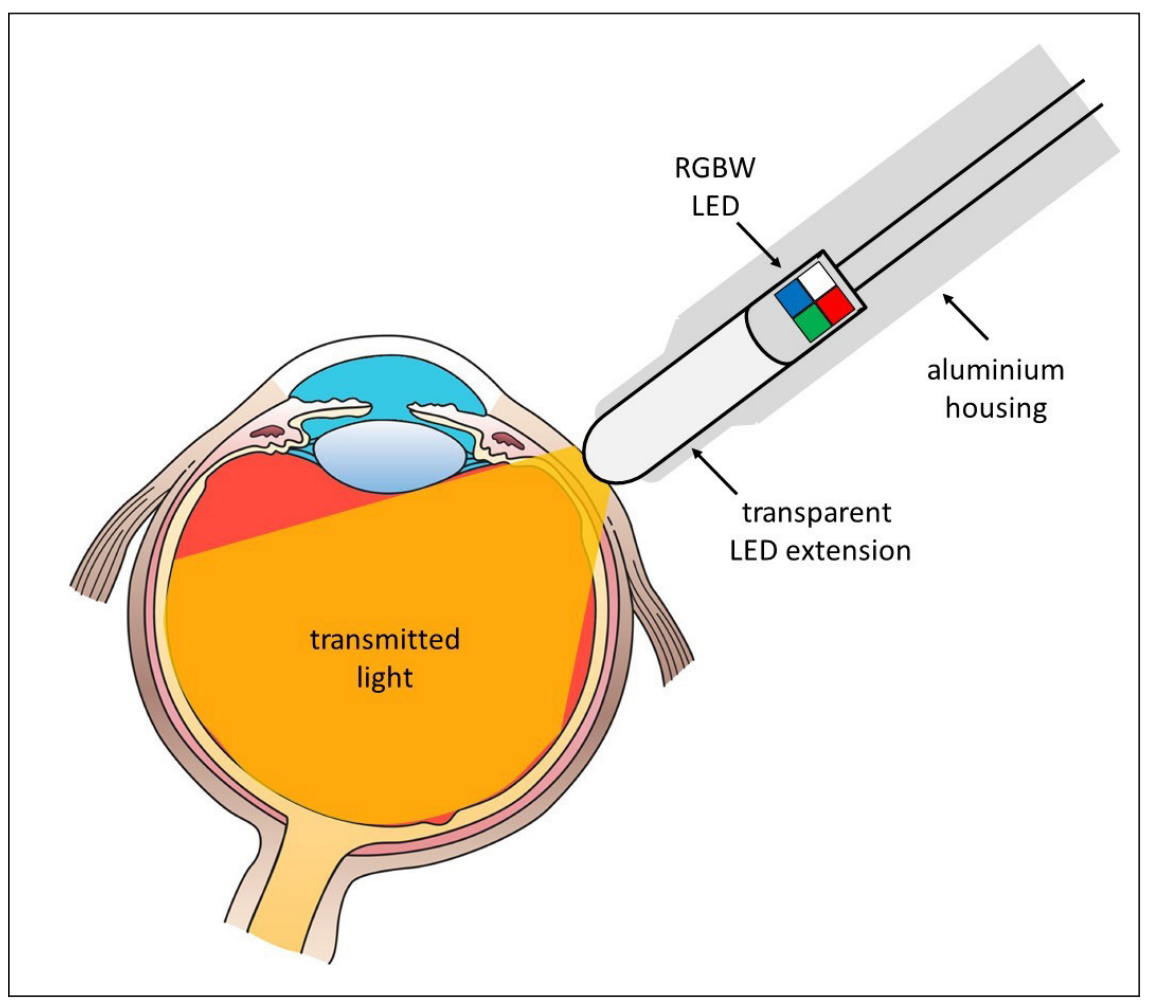

FIGURE 1. Scheme of the diaphanoscopic eye illumination with the extended red-green-blue-white light-emitting diode (RGBW-LED). Modified according to [17]

display type GEN4-4DPI-70CT-CLB of 4D Systems (Minchinbury, Australia). By this unit, an average current between 0 and $150 \mathrm{~mA}(0-100 \%)$ can be selected by pulse width modulation.

\section{RESULTS}

A photograph of the RGBW diaphanoscope prototype and its control unit is presented in Figure 2, and in Figure 3 the illumination of porcine eyes with different colors is depicted.

The emission spectra of the different LEDs for the maximum current are given in Figure 4. The maximum total power (for LEDs currents of $100 \%$ or $150 \mathrm{~mA}$ ), $\mathrm{E}_{\mathrm{A}-\mathrm{R}}, \mathrm{E}_{\mathrm{VIR}-\mathrm{R}}$, and the maximum exposure time - regarding a potential photochemical hazard - are compiled in Table 1. Due to the warming of the LEDs, the simultaneous emission of all LEDs (100\% RGBW) is lower than the sum of $100 \%$ emissions of the single LEDs.

The "weighted retinal visible and infrared radiation thermal irradiance" $\mathrm{E}_{\mathrm{VIR}-\mathrm{R}}$ - second row in Table 1 - is always below the limit of $0.7 \mathrm{~W} / \mathrm{cm} 2$ given by the standard DIN EN ISO 15004-2: 2007-6, so the thermal effect of the radiation poses no threat to the retina.
The situation for the "weighted retinal irradiance" $E_{A-R}$ is more complex. Most of the maximum values in the third row of Table 1 exceed the limit of $0.22 \mathrm{~mW} / \mathrm{cm}^{2}$ given in DIN EN ISO 15004-2: 2007-6. In this case, a maximum exposure time can be calculated according to formula (3). These maximum exposure times assume a direct contact to the retina, which is not the case for diaphanoscopic illumination from the outside. In fact, the light has to pass the sclera and choroidea before it reaches the retina, and both are known for their low transmission, especially for blue light. This strongly reduces retinal irradiation and increases the allowed exposure time. According to Koelbl et al. [19], the human sclera transmission is about $13.6,26.3$, and $33.7 \%$ for 450,530 , and $630 \mathrm{~nm}$ and a pressure of about $60 \mathrm{kPa}$. A lower estimate for the minimal exposure time - that does not consider the absorption of the choroidea - is given in the fourth row of Table 1. Even the $7 \mathrm{~min}$ for $100 \%$ blue LED emission exceeds the duration of usual diagnostic and therapeutic procedures at a single spot.

The measured maximum temperatures at the LED-tip are also given in Table 1 . The temperatures for $100 \%$ emission of the single LEDs were 


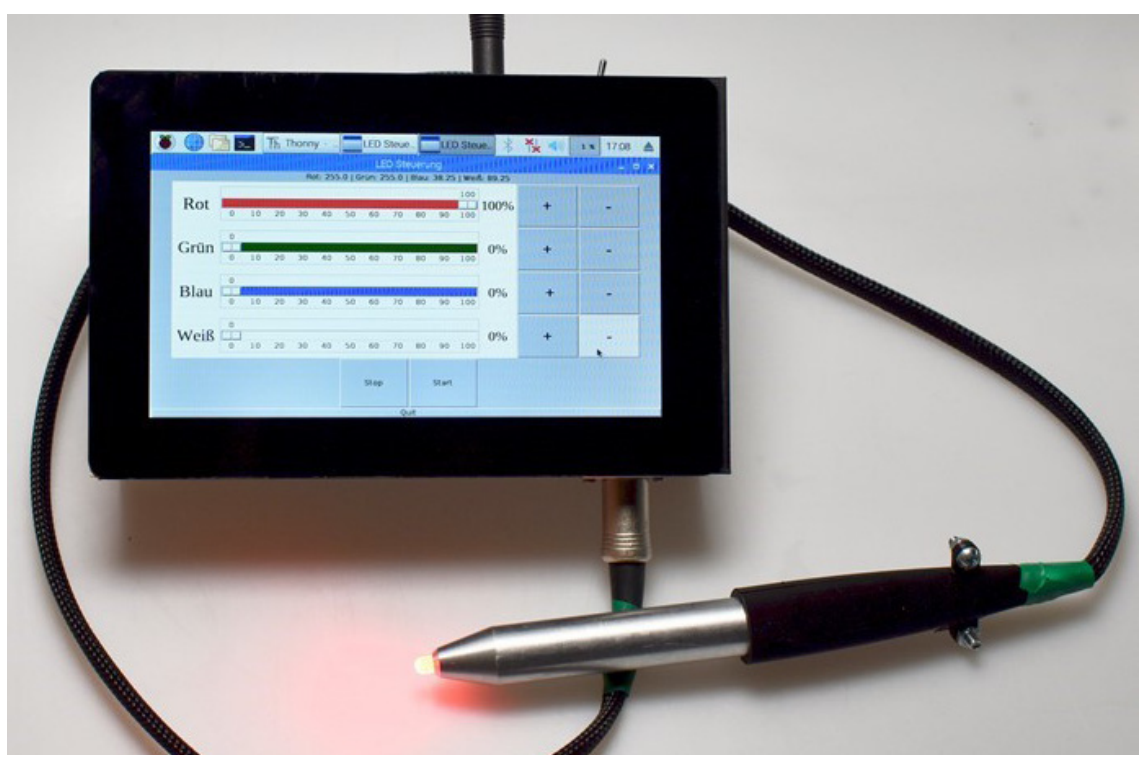

FIGURE 2. Photograph of the RGBW-LED diaphanoscope prototype

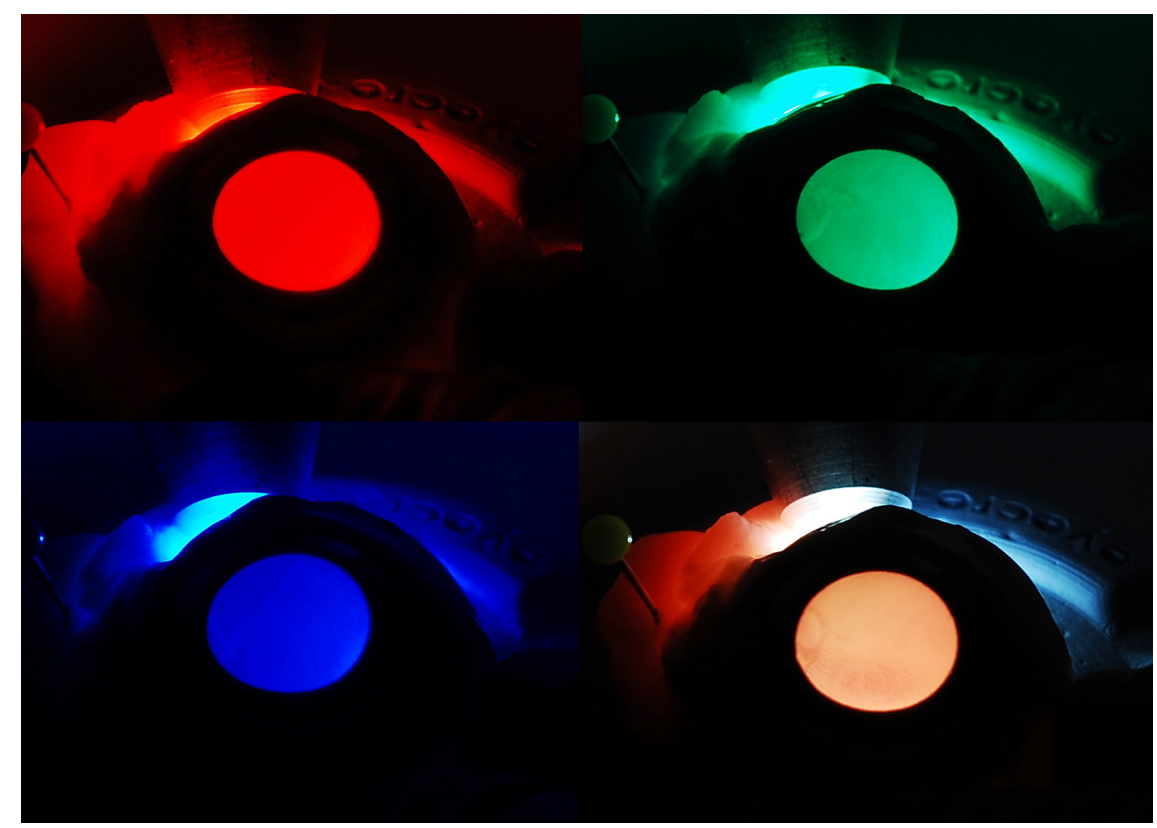

FIGURE 3. Photographs of a porcine eye transilluminated with the red, green, blue, and white light of the RGBW-LED diaphanoscope prototype

all about $32^{\circ} \mathrm{C}$, and for the RGBW-LED with the maximum current of $4 \times 150 \mathrm{~mA}(150 \mathrm{~mA}$ for each LED chip), the temperature reached $37^{\circ} \mathrm{C}$, which does not pose a threat to the patient.

\section{DISCUSSION AND CONCLUSION}

The developed RGBW-LED prototype provides a bright and adjustable illumination as demon- strated experimentally, at least in porcine eyes. This offers advantages compared to commercially available diaphanoscopes that usually consist of a xenon or halogen fiber light source with an applicator tip mounted to the end of the fiber. These systems offer a white illumination over a large spectral area. However, when this light passes the eyewall, a red-shift of the intraocular illumination is observed [4, 20-22] because blue light exhibits 


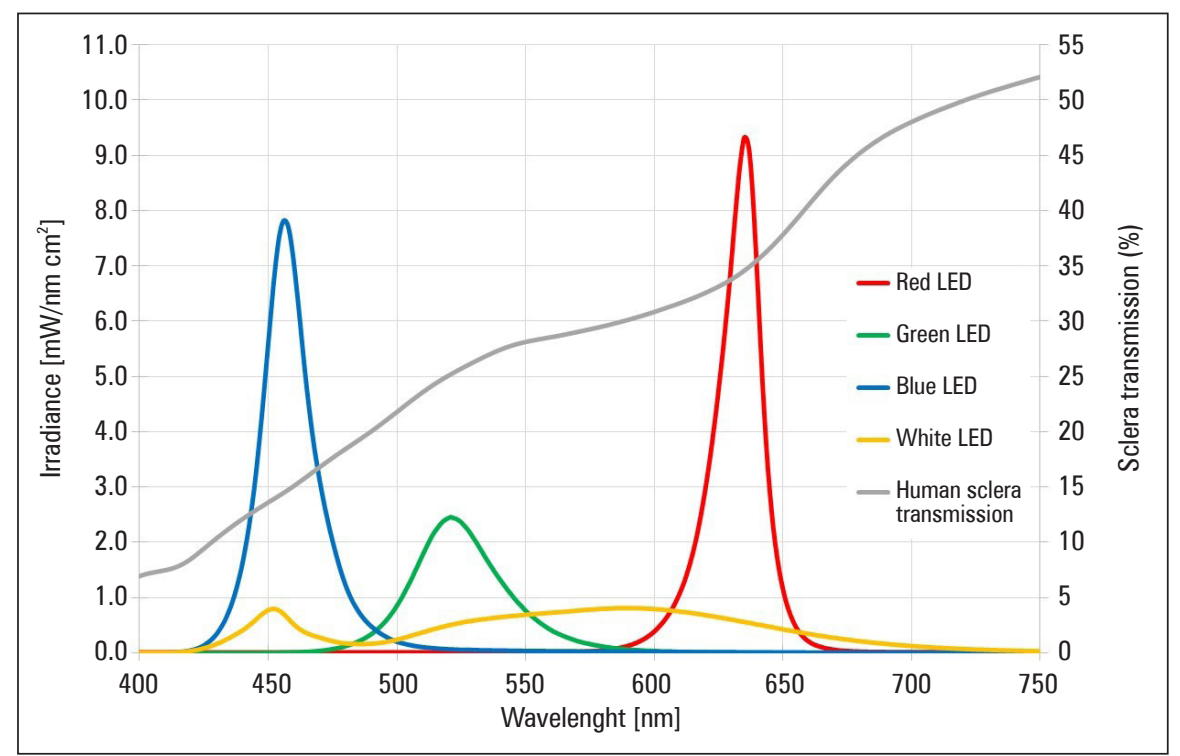

FIGURE 4. Measured irradiation spectra red (100\%), green (100\%), blue (100\%), and white $(100 \%)$ for an assumed direct contact to the sclera and human sclera transmission spectrum of Koelbl et al. [19]

Table 1. Luminous flux and irradiance on the eye at maximum current $(100 \%)$, and resulting $E_{V I R-R}$ and $E_{A-R}$ and resulting maximum exposure time in case of an assumed direct proximity to the retina (unrealistic), resulting maximum exposure time considering the sclera transmission spectrum of Koelbl et al. [19] (more realistic but still without choroidea absorption) and maximum temperature at the tip of the elongated LED

\begin{tabular}{|l|c|c|c|c|c|c|}
\hline LED & $\begin{array}{c}\text { Luminous flux } \\
{[\mathbf{I m}]}\end{array}$ & $\begin{array}{c}\mathbf{E}_{\text {VIR-R }} \\
{\left[\mathbf{m W} / \mathbf{n m ~ c m} \mathbf{~ c m}^{2}\right]}\end{array}$ & $\begin{array}{c}\mathbf{E}_{\mathrm{A}-\mathrm{R}} \\
{\left[\mathbf{m W} / \mathbf{n m ~ c m}^{2}\right]}\end{array}$ & $\begin{array}{c}\mathbf{t}_{\max } \\
{[\mathbf{m i n}]}\end{array}$ & $\begin{array}{c}\mathbf{t}_{\max }[\mathbf{m i n}] \text { with sclera } \\
\text { transmission }\end{array}$ & $\begin{array}{c}\text { LED tip temperature } \\
{\left[{ }^{\circ} \mathbf{C}\right]}\end{array}$ \\
\hline $100 \%$ red & 7.1 & 201.5 & 0.47 & 358 & 2251.2 & 32 \\
\hline $100 \%$ green & 10.2 & 107.0 & 5.39 & 30.9 & 132.5 & 32 \\
\hline $100 \%$ blue & 2.2 & 202.1 & 156.6 & 1.1 & 7.3 & 32 \\
\hline $100 \%$ white & 9.1 & 138.7 & 21.6 & 7.7 & 53.0 & 32 \\
\hline $100 \%$ RGBW & 15.0 & 344.0 & 121.2 & 1.4 & 9.0 & 37 \\
\hline
\end{tabular}

a stronger absorption in the different layers of the eyewall $[19,23]$ than red light.

The presented RGBW-LED diaphanoscope can at least partially compensate for this blue absorption by increasing the intensity of the blue LED chip. As can be concluded from Figure 3, even a totally blue intraocular illumination is possible. With the advantageous overlap between this blue LED emission and the absorption of fluorescein [24], this could be utilized, e.g., for fluorescein angiography [25]. Other LED settings might improve the visualization of other dyes and fluorophores.

An increased blue intensity also poses a higher burden to the retina. However, according to the standard DIN EN ISO 15004-2: 2007-6 no danger for a human patient is expected for time-limited employment. The blue LED poses the most significant hazard, and the time limit of about $7 \mathrm{~min}$ for $100 \%$ blue LED emission in Table 1 might sound short. However, these $7 \mathrm{~min}$ is the limit if the diaphanoscope stays in the same position for this period. If the physician moves the diaphanoscope, the 7 min clock starts again at the new spot. Additionally, the maximum exposure times given in Table 1 are only lower limits because the strong absorption of the choroidea, caused by hemoglobin with its high blue absorption [23], was neglected. Therefore, the intensity of the RGBW-LED diaphanoscope can probably still be increased considerably in potential future versions without posing a threat to the patients retina.

In this respect, this simple illumination system provides a wide range of ophthalmic applications in operation theatres or doctor's practices. It might even be a useful tool in the field, e.g., after natural disasters like earthquakes, floods, and volcano erup- 
tions, which might result in many injured patients and missing healthcare infrastructure for the examination or treatment of patients. The extensive application of light guide-based lighting devices with, e.g., xenon lamps seems rather unrealistic under such circumstances. Diaphanoscopic illumination at least places lower demands on the sterility of the environment and is nevertheless a useful tool for some expected cases, such as intraocular foreign bodies or retinal detachments, which were already diagnosed and treated by means of diaphanoscopy a hundred years ago $[1,4,10]$.

\section{Conflict of interest}

The authors declare no conflict of interest.

\section{Compliance with ethics guidelines}

All institutional and national guidelines for the care and use of laboratory animals were followed.

\section{Acknowledgment}

We are grateful for financial support from the German Federal Ministry of Economics and Technology within the ZIM joint project "Safe Light" (Grant number ZF4137902AK9). We would also like to express our thanks to Joerg Moisel and Ulla Wenzel for providing of and introduction to the spectroradiometer and Tobias Meurle for electronic support.

\section{Authorship}

All named authors meet the International Committee of Medical Journal Editors (ICMJE) criteria for authorship for this article, take responsibility for the integrity of the work as a whole, and have given their approval for this version to be published.

\section{REFERENCES}

1. Koch FHJ, Deuchler S, Singh P, et al. [Ophthalmic diaphanoscopy]. Ophthalmologe. 2017; 114(9): 857-864, doi: 10.1007/s00347-0170470-6, indexed in Pubmed: 28386639.

2. Hirschberg J. Zur Diagnose des Aderhautsarkoms. Clin BI f Augenheilk. 1905; 1905: 329-39.

3. Lange 0. Zur Diagnose des intraokularen Sarkoms. Klin Mbl Augenheilk. 1884; 1888: 410.

4. Langenhan F. Ohthalmodiahanoskoie. In: Landolt E. ed. Die Untersuchungsmethoden. Springer Vienna, Vienna 1920: 392-424.

5. Lindahl C. Über Durchleuchtungsmethoden zum Nachweis von Choroidealtumoren. Klin Mbl Augenheilk. 1922; 1922: 11-29.

6. Terasaki H, Miyake $Y$, Awaya S, et al. Identification of anterior uveal tumor border by transscleral transillumination and an ophthalmic endoscope. Am J Ophthalmol. 1997; 123(1): 138-140, doi: 10.1016/ s0002-9394(14)71012-8, indexed in Pubmed: 9186117.
7. Kjersem B, Krohn J, Krohn J, et al. A modified digital slit lamp camera system for transillumination photography of intraocular tumours. Br J Ophthalmol. 2012; 96(4): 475-477, doi: 10.1136/bjophthalmol-2011-301017, indexed in Pubmed: 22113190.

8. HARRIS D, BROCKHURST RJ. Localization of intraocular foreign bodies by transilumination, and by indirect ophthalmoscopy with scleral indentation. Can Med Assoc J. 1962; 87: 565-567, indexed in Pubmed: 13904825.

9. Neubauer H. Intraocular foreign bodies. Bright light operative localization. Int Ophthalmol Clin. 1968; 8(1): 205-209, indexed in Pubmed: 5731767.

10. Wood EH. Study of transillumination of the eye. Arch Ophthalmol. 1939; 22(4): 653-666, doi: 10.1001/archopht.1939.00860100137011.

11. Berens $C$. Transilluminators and illuminated retractors for retinal detachment and surgery. J Am Med Assoc. 1955; 159(16): 1532, doi: 10.1001/ jama.1955.02960330032010a, indexed in Pubmed: 13271110.

12. Osmond $\mathrm{AH}$. New electrode transilluminator. $\mathrm{Br} \mathrm{J}$ Ophthalmol. 1954; 38(12): 757-762, doi: $10.1136 / \mathrm{bjo} 0.38 .12 .757$, indexed in Pubmed: 13219258.

13. Veckeneer $M$, Wong D. Visualising vitreous through modified transscleral illumination by maximising the Tyndall effect. $\mathrm{Br} \mathrm{J}$ Ophthalmol. 2009; 93(2): 268-270, doi: 10.1136/bjo.2008.147306, indexed in Pubmed: 19174403.

14. Koch FH, Scholtz S, Koss M, et al. External illumination options for vitreoretinal service provided in the operating room, an ambulatory surgery center or in the office. Invest Ophthalmol Vis Sci. 2011; 52: 544.

15. Bamonte G, van den Biesen PR. Vitreous base visualisation through trans-scleral illumination with a standard 25-gauge light probe. Br J Ophthalmol. 2014; 98(2): 281-283, doi: 10.1136/bjophthalmol-2013-304087, indexed in Pubmed: 24326323.

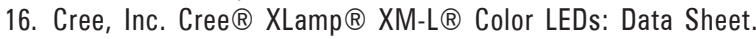
2019. https://www.cree.com/led-components/media/documents/ XLampXML_Color.pdf. (April 2021).

17. Fischer H. Three Internal Chambers of the Eye. 2013. http://upload.wikimedia.org/wikipedia/commons/archive/8/8a/20130204203139!Thr ee Internal chambers of the Eye.png?uselang=de (January 2021.).

18. DIN̄ EN ISO 15004-2:2007-06, Ophthalmische Instrumente Grundlegende Anforderungen und Prüfverfahren. Teil_2: Schutz gegen Gefährdung durch Licht (ISO_15004-2:2007); Deutsche Fassung EN ISO 15004-2:2007.

19. Koelbl PS, Klante P, Koch F, et al. Location and pressure dependent transmission of human and porcine sclera: an anterior to posterior examination. Graefes Arch Clin Exp Ophthalmol. 2017; 255(11): 2185-2198, doi: 10.1007/s00417-017-3758-y, indexed in Pubmed: 28779364.

20. Schirmer KE. Transillumination and Visualization of the Anterior Fundus. Archives of Ophthalmology. 1964; 71(4): 475-480, doi: 10.1001/ archopht.1964.00970010491006, indexed in Pubmed: 14109027.

21. Hessling M, Koelbl PS, Lingenfelder C, Koch F. Miniature LED endoilluminators for vitreoretinal surgery. In: Lilge LD, Sroka R. ed. European Conferences on Biomedical Optics; Sunday 21 June 2015. SPIE, Munich : 95421A.

22. Lingenfelder $C$, Koch $F$, Koelbl $P$, et al. Transscleral LED illumination pen. Biomed Eng Lett. 2017; 7(4): 311-315, doi: 10.1007/s13534017-0039-y, indexed in Pubmed: 30603181.

23. Koelbl PS, Sieber N, Lingenfelder C, et al. Pressure dependent direct transtissue transmission of eyewall, sclera and vitreous body in the range of $350-1050 \mathrm{~nm}$. Z Med Phys. 2020; 30(3): 201-210, doi: 10.1016/j.zemedi.2020.02.003, indexed in Pubmed: 32143979.

24. Sjöback R, Nygren J, Kubista M. Absorption and fluorescence properties of fluorescein. Spectrochimica Acta Part A: Molecular and Biomolecular Spectroscopy. 1995; 51(6): L7-L21, doi: 10.1016/05848539(95)01421-p.

25. Tsang SH, Sharma T. Fluorescein Angiography. Adv Exp Med Biol. 2018; 1085: 7-10, doi: 10.1007/978-3-319-95046-4_2, indexed in Pubmed: 30578475. 